\title{
Propuesta de alfabetización científica y tecnológica en torno al efecto inhibidor del extracto de aceite esencial de la toronja (citrus paradisi) en una comunidad agrícola del Municipio de Sutamarchán
}

Rodríguez Farias Angela Lizeth 1, Caballero Blanco Laura Juliana², Vélez Osorio Oscar Daniel $^{3}$

Categoria 2. Trabajo de investigación (en proceso)

\section{Resumen}

El presente trabajo de investigación esta fundamentado en la realizacion de una propuesta de alfabetización científica y tecnológica en una comunidad agrícola ubicada en el Municipio de Sutamarchan, en donde se busca que los trabajadores adquieran la capacidad de comprender los procesos llevados a cabo mecanicamente en su contexto laboral a partir de la implementación de una secuencia de enseñanza con enfoque CTSA, en donde se promueva la apropiación del conocimiento cientifico y tecnologico, generando un aporte al cambio cultural, y por tanto un buen manejo, utilización y cuidado del entorno en busca de la preservación del equilibrio medio ambiental. Esto se desarrollará a partir del posible efecto inhibidor del extracto de aceite esencial de la semilla y cascara de la toronja en el control de la mosca blanca en cultivos de tomate larga vida.

\section{Palabras clave}

Alfabetización cientifica y tecnologíca, secuencia de enseñanza, comunidad agricola, cambio cultural.

\section{Objetivos}

Objetivo general:

Contribuir en el proceso de alfabetización científica y tecnológica de una comunidad agrícola ubicada en el Municipio de Sutamarchán, a partir de una secuencia de enseñanza con enfoque CTSA fundamentada en el posible efecto inhibidor del extracto de aceite esencial de la semilla y cascara de la toronja en el control de la mosca blanca en cultivos de tomate larga vida.

\footnotetext{
1 Universidad Pedagógica Nacional. dqu_arodriguez575@pedagogica.edu.co

2 Universidad Pedagógica Nacional. dqu_lcaballero912@pedagogica.edu.co

3 Universidad Pedagógica Nacional.dqu_ovelez363@pedagogica.edu.co
} 
Revista Tecné, Episteme y Didaxis: TED. Año 2014, Número Extraordinario. ISSN Impreso: 0121-3814, ISSN web: 2323-0126

Memorias, Sexto Congreso Internacional sobre Formación de Profesores de Ciencias. 08 al 10 de octubre de 2014, Bogotá

Objetivos específicos:

Determinar el nivel inicial de alfabetización científica y tecnológica de los trabajadores en torno al control de plagas y sus implicaciones.

Diseñar e implementar una secuencia de enseñanza desde las relaciones CTSA que permita incrementar el nivel de alfabetización científica y tecnológica de la comunidad agrícola.

Evaluar la efectividad inhibidora del extracto de aceite esencial de la cáscara y semilla de toronja en el control de la mosca blanca en cultivos de tomate larga vida.

Analizar la contribución en el proceso de alfabetización científica y tecnológica a partir de los avances conceptuales, procedimentales y actitudinales evidenciados en la comunidad agrícola.

\section{Marco teórico}

A continuación se presentan los componentes teóricos bajo los cuales se fundamenta el presente trabajo de investigación:

\section{Alfabetización cientifica y tecnologica (ACT)}

Ante las demandas que plantean los nuevos retos educativos para el siglo XXI, la enseñanza de las ciencias viene recurriendo en los últimos años con insistencia a lemas como alfabetización científica y tecnológica, comprensión pública de la ciencia, ciencia para todas las personas, cultura científica y tecnológica, educación CTS (Ciencia, Tecnología y Sociedad), etc. ((Membiela, 2002) en (Acevedo Díaz, Vasquez Alonso, \& Manassero Mas, 2003)).La alfabetización científica debe ser concebida, como un proceso de "investigación orientada" que, superando el reduccionismo conceptual permita a los alumnos participar en la aventura científica de enfrentarse a problemas relevantes y (re)construir los conocimientos científicos, que habitualmente la enseñanza transmite ya elaborados, lo que favorece el aprendizaje más eficiente y significativo (Sabariego del Castillo \& Manzanares Gavilán, 2006).

Paulo Freire propone una alfabetización crítica y emancipadora que sea entendida como una construcción social y un proyecto ético-político, por el cual los individuos y las comunidades amplían sus posibilidades de vida y libertad, construyendo identidades personales y sociales, por medio de una conciencia crítica y al participar de manera activa en la lectura de su realidad, por lo tanto la alfabetización se constituye como un acto puramente político, creativo y 
Revista Tecné, Episteme y Didaxis: TED. Año 2014, Número Extraordinario. ISSN Impreso: 0121-3814, ISSN web: 2323-0126

Memorias, Sexto Congreso Internacional sobre Formación de Profesores de Ciencias. 08 al 10 de octubre de 2014, Bogotá

emancipador (Freire, 1968). Desde esta perspectiva, La necesidad de una alfabetización científica y tecnológica de todas las personas, requiere la incorporación de la dimensión CTSA en el currículo; es por esta razón, que la didáctica de las ciencias ha propuesto para el mejoramiento de la enseñanza la perspectiva CTSA, cuyo propósito central es promover la AC de todos los ciudadanos. El enfoque CTSA es un campo de estudio e investigación que permite que el estudiante comprenda la relación entre la ciencia con la tecnología y su contexto socio-ambiental (Martínez, Villamil, \& Peña, 2006). El objetivo principal de la aplicación de dicho enfoque es permitir a través de la alfabetización científica y tecnológica un cambio de actitud en los participantes en el acto educativo.

\section{Secuencia de enseñanza}

El criterio de secuenciación se refiere a propuestas que promueven acercamientos sucesivos a los contenidos, desde distintos contextos y significados, en forma integral, para ir de un todo indiferenciado y confuso, por sucesivas aproximaciones, a un todo con mayor diferenciación. "En función de esto, el maestro va a proponer y organizar series de situaciones didácticas que van a plantear obstáculos, que ponen en cuestión las concepciones previas de los estudiantes, de manera tal que se vaya haciendo posible que estas concepciones se acerquen progresivamente a la naturaleza del saber científico o socialmente constituido" (Lerner, 1995) .

Para la estructura de las secuencias de enseñanza aprendizaje Linjse (2000) citado en (Zenteno Mendoza \& Garritz, 2010) recomienda que esta debe desarrollarse en tres niveles fundamentales: el de contenido, el motivacional y el nivel de reflexión; para ello es importante incluir dentro de la secuencia toda una serie de estrategias, técnicas y actividades que permitan alcanzar los objetivos.

\section{Toronja (citrus paradisi)}

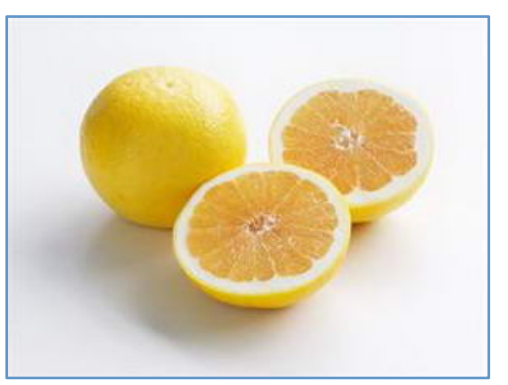

Imagen No 1. Toronja citrus paradisi. Tomado de http://provefru.com/
La Toronja Citrus paradisi (variedad Duncan) es proveniente de un árbol vigoroso, grande y muy productivo. Tiene un sabor excelente, pulpa muy firme y jugosa, buena acidez y niveles de azúcar elevados, dando un sabor equilibrado, rico y dulce. Contiene un elevado número de semillas (30-50 por fruto). En cuanto a las propiedades estos cítricos se caracterizan fundamentalmente por sus frutos grandes que contienen cantidades abundantes de ácido cítrico componente con formula $\mathrm{C}_{3} \mathrm{H}_{4} \mathrm{OH}(\mathrm{COOH})_{3}$, el cual les proporciona el característico sabor acido. Además 
Revista Tecné, Episteme y Didaxis: TED. Año 2014, Número Extraordinario. ISSN Impreso: 0121-3814, ISSN web: 2323-0126

Memorias, Sexto Congreso Internacional sobre Formación de Profesores de Ciencias. 08 al 10 de octubre de 2014, Bogotá

todos los miembros del genero citrus contiene otros componentes que les otorgan aromas muy profundos (Gergensen \& Leon, 1999 en (Yañez Rueda et al, 2006)) como los ácidos málico, oxálico, tartárico y cítrico, éste último potencia la acción de la vitamina $C$.

\section{Aceite esencial de la toronja como plaguicida de origen natural}

Los aceites esenciales obtenidos de frutos cítricos son mezclas de aproximadamente 100 componentes, los cuales dependen de la variedad de fruta y del método de extracción empleado. La presencia de estos en las plantas les proporciona una importante defensa estratégica, particularmente contra insectos herbívoros y hongos patógenos (Langenheim, 1994 en (Espitia Yanes, 2011)). Esta característica es precisamente aprovechada para el desarrollo de productos de utilidad agrícola y alimentaria, con el objeto de controlar el significativo número de plagas que afectan tanto cosechas como semillas ya almacenadas. Los aceites esenciales son líquidos volátiles, en su mayoría insolubles en agua, pero fácilmente solubles en alcohol, éter, aceites vegetales y minerales. En un aceite esencial pueden encontrarse hidrocarburos alicíclicos y aromáticos, así como sus derivados oxigenados, por ejemplo, alcoholes, aldehídos, cetonas, ésteres, sustancias azufradas y nitrogenadas. Los compuestos más frecuentes derivan biológicamente del ácido mevalónico y se les cataloga como terpenos, siendo los más abundantes los monoterpenos (C10) y los sesquiterpenos (C15) (Yáñez Rueda et al, 2006).

\section{Tomate larga vida (solanum lycopersicum I.}

La introducción de los genes Nor y Rin son los responsables de su larga vida, confiriéndole mayor consistencia y gran conservación de los frutos de cara a su comercialización. Dicha hortaliza contiene aproximadamente un $94 \%$ de agua, y el $6 \%$ restante es una mezcla compleja en la que predominan los azúcares libres y ácidos orgánicos, que contribuyen a dar al fruto su textura y sabor característicos (Coronel, 2009 y León, 2009 en (Hernandez Yepez, 2013)). Las condiciones climáticas, imperantes en las diferentes regiones principalmente en las épocas de sequía o lluvia, afectan la productividad de los cultivos, debido a los cambios extremos de temperatura y humedad relativa

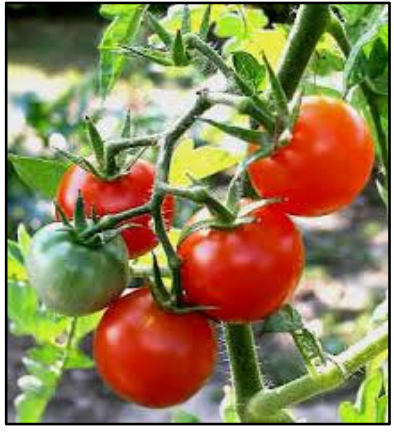

Imagen No. 2. Cultivos de tomate. Tomado de

http://www.noticiasrur favoreciendo el ataque de plagas y enfermedades, lo que lleva al productor a la utilización de mayor cantidad de pesticidas y fertilizantes para lograr altas productividades, incrementando los costos de producción, disminuyendo la rentabilidad y causando graves daños de contaminación al medio ambiente. 
Revista Tecné, Episteme y Didaxis: TED. Año 2014, Número Extraordinario. ISSN Impreso: 0121-3814, ISSN web: 2323-0126

Memorias, Sexto Congreso Internacional sobre Formación de Profesores de Ciencias. 08 al 10 de octubre de 2014, Bogotá

\section{Mosca blanca (Trialeurodes vaporarioum y Bemisia tabaci}

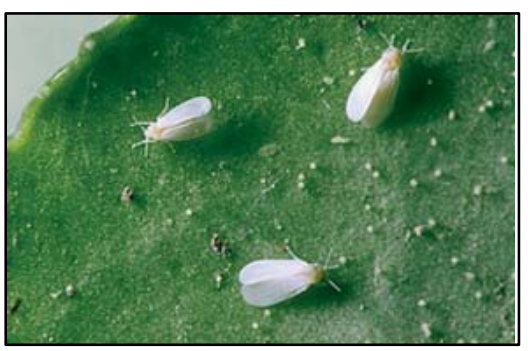

Imagen No. 3. Mosca Blanca. Tomado de (Suarez Gomez \& Bolaño Amaya, 1999)

La mosca blanca es la plaga más común y limitante en el cultivo de tomate bajo invernadero, especialmente en épocas secas. Su denominación como plaga, radica en el daño causado por adultos e inmaduros, al succionar la savia de la planta. Esto, debido a que ingiere los jugos proteicos y expele los excesos de azúcar en forma de mielecilla, favoreciendo el desarrollo del hongo Cladosporium causante de la fumagina en las hojas. Cuando la infestación es fuerte, esta cubre hojas, reduciendo la fotosíntesis y cubre los frutos, los cuales deben ser limpiados antes de su comercialización (Suarez Gomez \& Bolaño Amaya, 1999).

\section{Metodología}

El presente trabajo de investigación se encuentra enmarcado bajo la línea de investigación del departamento de química de la Universidad Pedagógica Nacional Alternaciencias: Enseñanza de las Ciencias con enfoque CTSA y enculturación científica. El tipo de investigación en el cual se encuentra basado es de tipo mixto, cuasi experimental sin grupo control. Esta investigación se realiza con el fin de contribuir en el proceso de ACT en una comunidad agrícola por medio del diseño, implementación y análisis de una secuencia de enseñanza con enfoque CTSA en torno al posible efecto inhibidor del extracto de aceite esencial de la cáscara y semilla de la toronja en el control de mosca blanca en cultivos de tomate larga vida. El desarrollo metodológico de la presente investigación se encuentra fundamenta do en cuatro fases, las cuales se describen a continuación:

Figura 1. Fases de la investigación 
Revista Tecné, Episteme y Didaxis: TED. Año 2014, Número Extraordinario. ISSN Impreso: 0121-3814, ISSN web: 2323-0126

Memorias, Sexto Congreso Internacional sobre Formación de Profesores de Ciencias. 08 al 10 de octubre de 2014, Bogotá

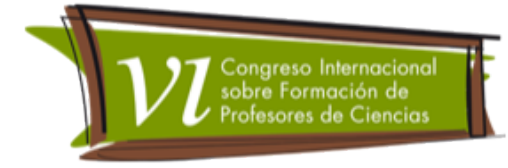

Fase 1:

Caracterización

de la población
- Objetivo: Identificar en los trabajadores las características personales como rango de edad, sexo, grado de escolaridad, lugar de vivienda, cargo y funciones que desempeñan dentro de la organización. Ademas determinar el nivel de alfabetización científica inicial.
Fase 2: Selección y diseño de las actividades de la secuencia de enseñanzo
- Objetivo: Diseñar la secuencia de enseñanza a partir de la selección de cada una de las actividades relacionadas con el enfoque CTSA y su vínculo con los cultivos en torno al posible efecto inhibidor del extracto de aceite esencial de toronja en el control de mosca blanca en tomate larga vida.

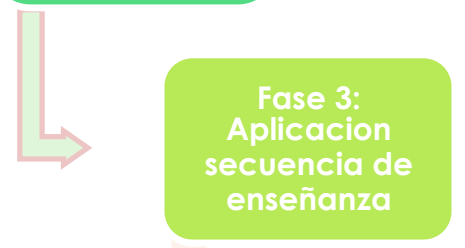

- Objetivo: Comprender, reflexionar y analizar las implicaciones de las relaciones CTSA con la mitigación de plagas, manejo de desechos orgánicos, impactos en la salud e innovación científica y tecnológica permitiendo contribuir con una educación multidimensional que genere un conocimiento significativo de su entorno laboral.

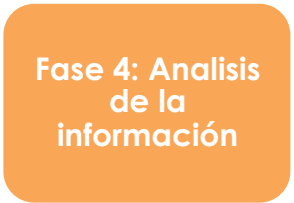

Objetivo: Identificar y analizar el nivel de alfabetizacion cientifica y tecnologica que fue adquirido por los diferentes trabajadores a partir de la aplicación de la secuencia de enseñanza con enfoque CTSA 
Revista Tecné, Episteme y Didaxis: TED. Año 2014, Número Extraordinario. ISSN Impreso: 0121-3814, ISSN web: 2323-0126 Memorias, Sexto Congreso Internacional sobre Formación de Profesores de Ciencias. 08 al 10 de octubre de 2014, Bogotá

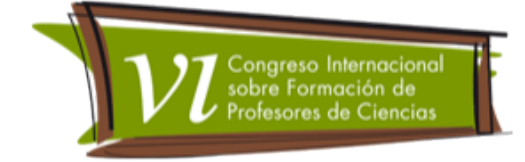

\section{Resultados esperados}

Al finalizar el proceso desarrollado en la comunidad agricola a partir de la implementacion de una secuencia de enseñanza basada en el posible efecto inhibidor del extracto de aceite esencial de la cáscara y semilla de la toronja para el control de la mosca blanca en cultivos de tomate larga vida, el trabajador tendrá la capacidad de llevar una conciencia social, tecnológica y ambiental basada en conocimientos adquiridos de forma significativa, dandoles la posibilidad de reflexionar y construir argumentos que le permitan asumir una postura en relaciòn a la preservacion del equilibrio medio ambiental.

\section{Referencias bibliográficas}

Acevedo Díaz, J. A., Vasquez Alonso, A., \& Manassero Mas, M. A. (2003). Papel de la educación CTS en una alfabetización Científica y Tecnológica para todas las personas. Revista Electrónica de Enseñanza de las Ciencias, 80 111

Espitia Yanes, C. R. (2011). Evaluacion de la actividad repelente e insecticida de aceites esenciales extraidos de plantas aromaticas. Cartagena de Indias: Universidad Nacional de Colombia

Fourez, G. (1997). Alfabetización Científica y tecnológica. Acerca de las Finalidades de la enseñanza de las Ciencias. Buenos Aires: Colihue

Freire, P. (1968). Educación como práctica libertadora. Rio de Janeiro : Paz e Tierraa

Hernandez Yepez, J. N. (2013). Caracterizacion fisico-quimica y microbiologica del tomate margariteño y evaluacion de la efectividad de tratamientos de pre-envasado para el incremento de su vida comercial a temperatura ambiente. Cordoba: Servicio de publicaciones de la Universidad de Cordoba

Lerner, D. (1995). El aprendizaje y la enseñanza de la matemática. Planteos actuales. Revista Novedades Educativas(52)

Sabariego del Castillo, J. M., \& Manzanares Gavilán, M. (2006). Alfabetización Científica. I Congreso Iberoamericano de Ciencia, Tecnológia, Sociedad e Innovación CTS + I. Mexico 
Revista Tecné, Episteme y Didaxis: TED. Año 2014, Número Extraordinario. ISSN Impreso: 0121-3814, ISSN web: 2323-0126

Memorias, Sexto Congreso Internacional sobre Formación de Profesores de Ciencias. 08 al 10 de octubre de 2014, Bogotá

Suarez Gomez, H. D., \& Bolaño Amaya, R. E. (1999). Manejo de la mosca blanca en el cultivo del tomate en el Norte del Cesar. Valledupar, Cesar: Corpoica Regional 3

Zenteno Mendoza, B. E., \& Garritz, A. (2010). Secuencias Dialógicas, la dimensión CTS y asuntos socio - Científicos enla enseñanza de la química. Revista Eureka sobre Enseñanza y Divulgación de las Ciencias, $2-25$ 